\title{
PNEUMOCONIOSIS AND RESPIRATORY PROBLEMS IN DENTAL LABORATORY TECHNICIANS: ANALYSIS OF 893 DENTAL TECHNICIANS
}

\section{DILEK ERGÜN ${ }^{1}$, RECAI ERGÜN², CENGIZ ÖZDEMIR ${ }^{3}$, TÜRKAN NADIR ÖZIŞ', HINÇ YILMAZ4, and İBRAHIM AKKURT ${ }^{5}$}

${ }^{1}$ Ankara Occupational Diseases Hospital, Ankara, Turkey

Department of Chest Diseases

${ }^{2}$ Ministry of Health of the Republic of Turkey Training and Research Hospital, Ankara, Turkey

Chest Diseases Clinic

${ }^{3}$ Istanbul Yedikule Chest Diseases and Chest Surgery Training and Research Hospital, Istanbul, Turkey

Chest Diseases Clinic

${ }^{4}$ Ankara Occupational Diseases Hospital, Ankara, Turkey

Department of Toxicology

${ }^{5}$ Akay Hospital, Ankara, Turkey

Chest Diseases Clinic

\begin{abstract}
Objectives: To explore the rate of pneumoconiosis in dental technicians (DTP) and to evaluate the risk factors. Material and Methods: Data of 893 dental technicians, who were admitted to our hospital in the period January 2007-May 2012, from 170 dental laboratories were retrospectively examined. Demographic data, respiratory symptoms, smoking status, work duration, working fields, exposure to sandblasting, physical examination findings, chest radiographs, pulmonary function tests and high-resolution computed tomography results were evaluated. Results: Dental technicians' pneumoconiosis rate was $10.1 \%$ among 893 cases. The disease was more common among males and in those exposed to sandblasting who had 77-fold higher risk of DTP. The highest profusion subcategory was $3 /+$ (according to the International Labour Organization (ILO) 2011 standards) and the large opacity rate was 13.3\%. Conclusions: To the best of our knowledge, it was the largest DTP case series $(\mathrm{N}=893 / 90)$ in the literature in English. Health screenings should be performed regularly for the early diagnosis of pneumoconiosis, which is an important occupational disease for dental technicians.
\end{abstract}

Key words:

Pneumoconiosis, Dental laboratory technicians, Occupational respiratory disease, Pulmonary function,

High-resolution computed tomography

Received: February 4, 2014. Accepted: May 7, 2014.

Corresponding author: R. Ergün, Ministry of Health of the Republic of Turkey Training and Research Hospital, Chest Diseases Clinic, İfan Baştuğ 10, 06340 Ankara, Turkey (e-mail: recaiergun@gmail.com). 


\section{INTRODUCTION}

Dental staff is exposed to various physical, chemical and biological harmful conditions in the working environment $[1,2]$. Defining the working conditions and risks that are likely to be experienced is mandatory in order to take work-related preventive measures. Dental technicians are exposed to numerous potential toxic substances and airborne residuals (including silica, alloys and acrylic-plastics) in the working environment. As a consequence, dental technicians develop occupational lung diseases such as asthma, bronchial cancer, mesothelioma and pneumoconiosis depending inter alia on the duration of exposure [3,4].

Pneumoconiosis is a disease that results from accumulation of inhaled particles in the lungs. Many substances such as asbestos, coal dust, silica, beryllium, cobalt, tungsten carbide, and iron oxide cause pneumoconiosis [5]. Silicosis has been reported as one of the most common pneumoconiosis among dental technicians [6]. Nevertheless, dental technicians' pneumoconiosis (DTP) is considered as a specific entity and thought to be associated with exposure to cobalt-chromium-molybdenum (CoCrMo) [7].

Pneumoconiosis is an important occupational disease with potential fatal outcomes. Besides, it is also known that the frequency of tuberculosis and cancer is higher in pneumoconiosis cases as compared to the normal population [8-11]. Thus, it is necessary to make an early diagnosis, know the risk factors, and take preventive measures to decrease the mortality and morbidity rates of the disease. Chest radiographs have been used for a number of years for the screening and pre-diagnosis of occupational lung diseases. Nevertheless, it is known that computerized tomography $(\mathrm{CT})$ is more sensitive in detecting pleura-parenchymal abnormalities in pneumoconiosis. Moreover, in order to detect pneumoconiosis lesions, high-resolution CT (HRCT), which is a more sensitive diagnostic tool is used [12-14].

Our hospital is one of the 3 reference centers for the final legal diagnosis of occupational diseases in Turkey.
As in many other developing countries, there are many unlicensed dental prosthesis laboratories. Therefore, the number of dental prosthesis technicians is not exactly known. However, it is estimated there are 2500-3000 dental prosthesis laboratories and nearly 12000 dental prosthesis technicians. In accordance with the statutes of the Ministry of Health, chest radiographs of these technicians are taken every 2 years for pneumoconiosis screening and sent by mail to 3 reference centers. Our hospital is one of these centers and people with suspicious lesions in chest radiographs are referred to our hospital for further investigations.

The aim of the present study was to explore the rate of pneumoconiosis among dental technicians admitted to our hospital for the screening of pneumoconiosis, and to evaluate the results of respiratory function tests, chest radiographs and HRCT, as well as the risk factors that influence the development of pneumoconiosis.

\section{MATERIAL AND METHODS}

Data of 893 dental technicians, who came to the outpatient clinic of Ankara Occupational Diseases Hospital between January 2007 and May 2012, from 170 dental laboratories affiliated to the provincial directory of health, were retrospectively evaluated. The majority of dental technicians were working in small places with inadequate ventilation. They were exposed to a lot of dust as many procedures were carried out simultaneously. Patients with active tuberculosis or a history of the disease were not included in the study. The diagnosis of pneumoconiosis was based on the history of exposure to a mixture of dust and radiological changes consistent with pneumoconiosis.

In addition to demographic data, respiratory symptoms, smoking status, total work duration, working fields, exposure to sandblasting, physical examination findings, chest radiographs, and results of pulmonary function tests (PFTs) were recorded on the evaluation form. The 
study was approved by the Human Ethics Committee of the Ministry of Health of the Republic of Turkey Training and Research Hospital, Ankara, Turkey.

Working fields were evaluated in 4 groups:

- modeling department (modeling, muffle, installation, porcelain, wax studies),

- leveling and polishing department (trimming, polishing, sandblasting, prosthesis, casting studies),

- plaster and revetment department,

- administrative division (courier, director, etc.).

Individuals non-smoking for a year or longer were considered as ex-smokers, those smoking 1 or more cigarettes a day for at least one year were considered as smokers, and those smoking less or none were considered as nonsmokers. PFTs were interpreted in accordance with the American Thoracic Society standards [15]. A standard spirometry measurement was done using dry-seal-spirometry (Zan 100, nSpire Health Inc., Oberthulba, Germany). The spirometry device was calibrated by measuring the humidity and temperature of the environment prior to each measurement. A forced vital capacity (FVC) maneuver was performed in each subject according to the standard procedure.

Postero-anterior (PA) chest X-rays were taken in the radiology clinic of our hospital. A technique with short exposure time and with high voltage (Trophy UFXRAY, $500 \mathrm{~mA}$, TM) was used. PA chest X-rays were evaluated in accordance with International Labour Organization (ILO) 2011 standards [16] by 3 B readers ( 2 chest disease specialists and a radiologist) and an A reader, i.e., a general practitioner. If there was any inconsistency between the 4 readers, they re-evaluated the PA chest X-rays. All of the X-rays were quality 1 or 2 according to the ILO classification. Those with ILO category $1 / 0$ and over were considered as pneumoconiosis. After standard radiographs were compared, profusion was assessed and recorded as: $0(0 /-; 0 / 0 ; 0 / 1)$, $1(1 / 0 ; 1 / 1 ; 1 / 2), 2(2 / 1,2 / 2,2 / 3)$ or $3(3 / 2 ; 3 / 3 ; 3 /+)$.
The shape and size were evaluated by comparing standard radiographs. The predominant shape and size were expressed as $\mathrm{p}, \mathrm{q}, \mathrm{r}, \mathrm{s}, \mathrm{t}$ or $\mathrm{u}$. Large opacities and complete classification were noted as size A, B or C [16]. All subjects, whose X-rays were suspicious in terms of DTP, underwent thoracic HRCT. A GE HiSpeed scanner (General Electric Medical Systems, Milwaukee, HI spit NXI, Milwaukee, Wisconsin, USA) was used for the HRCT. Slices in $1 \mathrm{~mm}$ size at $1.5 \mathrm{~s}$ intervals which increased by $10 \mathrm{~mm}$, image reconstruction with a $512 \times 512$ px matrix with the use of a high-resolution algorithm, and 1000 Hounsfield unit (HU) width were used.

Data were analyzed using the Statistical Package for the Social Sciences (SPSS Inc., Chicago, IL, USA) version 15.0. Descriptive statistics were presented as cross-tables for categorical variables and as mean, median, standard deviation, minimum and maximum for numerical variables. Independent categorical variables were compared using the $\mathrm{Chi}^{2}$ test. In the case the $\mathrm{Chi}^{2}$ condition was not met, the Monte Carlo Simulation was used for multiple comparisons, and the Fisher's exact test was used for paired comparisons. In case the normal distribution condition was not met, the MannWhitney $U$ test was used for paired comparison of numerical variables, whereas the Kruskal-Wallis test was used for the comparison of multiple groups. Subgroup comparisons were performed using the Mann-Whitney U test with the Bonferroni correction.

In order to determine the risk factors, the Backward-Stepwise method and logistic regression analysis were used for categorical dependent variables and the Enter method and linear regression analysis were used for numerical dependent variables. A p value $<0.05$ was considered significant.

\section{RESULTS}

The study comprised 893 dental technicians (726 males, 167 females) with a mean age of $34.7 \pm 8.5$ years. None of the dental technicians had previous dust exposure in their occupational history. 
Pathological signs were detected on the chest X-rays of $90(10.1 \%)$ patients out of 888 . Chest X-rays could not be taken in 5 patients due to pregnancy. Pulmonary function test could not be performed in 10 patients due to a compliance problem. Among the 883 patients that underwent PFT, 30 (3.4\%) had restrictive and $71(8 \%)$ had obstructive signs, whereas the results of $782(87.6 \%)$ PFTs were unremarkable. Consequently, 10.1\% ( $\mathrm{N}=90)$ of dental technicians were considered to have pneumoconiosis. We evaluated 171 cases with sandblasting history as a special subgroup. Seventy-nine of these cases (46.1\%) had radiological pneumoconiosis findings. The comparison of the characteristics of all dental technicians with or without pneumoconiosis is presented in Table 1 .

The rate of males was remarkably high and the rate of smokers and the number of consumed cigarettes were significantly high among those with DTP. Overall respiratory tractrelated complaints were more frequent in those with DTP. The rate of exposure to sandblasting was also significantly high in those with DTP. There was no significant difference between groups in terms of overall duration of work, while duration of work in the leveling and polishing department was found to be significantly higher in those with DTP.

The rate of impaired PFT (obstructive, restrictive) was significantly higher in those with DTP as compared to those without DTP. The mean results of PFTs, except for FVC and peak expiratory flow (PEF), were significantly lower in those with DTP (Table 2).

The profusion category, shape, size, and zone of small opacities on the X-rays, as well as ILO classification of large opacities, are presented in Table 3.

Among those with DTP, $40 \%$ had category 1, 35.6\% had category 2 , and $24.4 \%$ had category 3 profusion, whereas $48.9 \%$ had p, $43.3 \%$ had q, $4.4 \%$ had r, 1.1\% had s, and $2.2 \%$ had u opacity. Out of the large opacities, 3.3\% was A, 3.3\% was B, and 6.7\% was C opacity (Photo 1 and 2). While all zones were involved in $56.7 \%$ of the subjects, the lesions were located in the upper zone in $35.6 \%$.

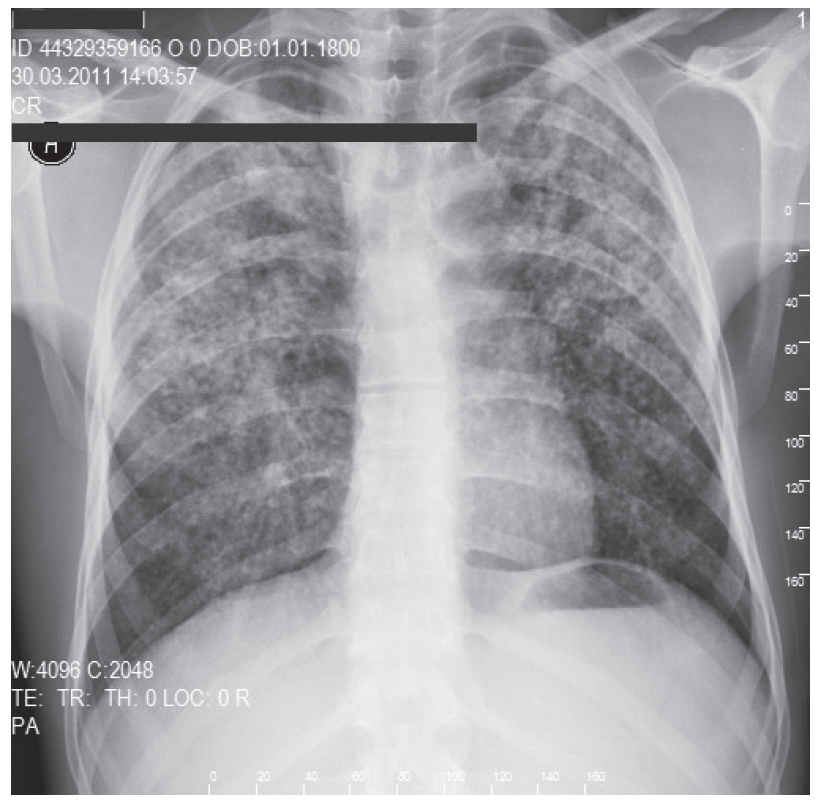

Photo 1. Postero-anterior (PA) chest X-ray of a 38-year-old male dental technician, who had been working in a leveling and sandblasting department for 24 years $(\mathrm{r} / \mathrm{r} 3 / 3+\mathrm{C}$ as in Table 3$)$

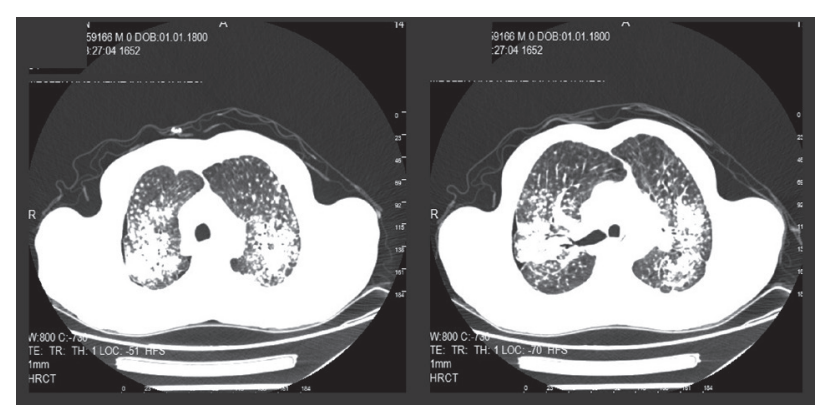

Photo 2. High-resolution computed tomography sections of the patient mentioned in Photo 1 - large opacities in 2 separate sections

High-resolution CT evaluations revealed that the rates of subjects with hilar lymphadenopathy (LAP), mediastinal LAP, micronodule, reticulonodular infiltration, linear density increment, and interlobular septal thickening were higher among those with DTP (Table 4).

The model created by including the age at the start of employment, male gender, total work time, smoking status, duration of work in each department (work experience), and exposure to sandblasting to determine the risk factors 
Table 1. Characteristics of dental technicians and comparison of the characteristics of those with and without dental technicians' pneumoconiosis

\begin{tabular}{|c|c|c|c|c|}
\hline Variable & $\begin{array}{l}\text { All dental technicians } \\
\qquad(\mathrm{N}=893)\end{array}$ & $\begin{array}{l}\text { Without DTP } \\
(\mathrm{N}=803)\end{array}$ & $\begin{array}{l}\text { With DTP } \\
(\mathrm{N}=90)\end{array}$ & $\mathrm{p}^{*}$ \\
\hline Age (years) $(\mathrm{M} \pm \mathrm{SD})$ & $34.7 \pm 8.5$ & $34.7 \pm 8.7$ & $34.9 \pm 6.9$ & 0.624 \\
\hline Gender $[\mathrm{n}(\%)]$ & & & & $<0.001$ \\
\hline female & $167(18.7)$ & $166(20.7)$ & $1(1.1)$ & \\
\hline male & $726(81.3)$ & $637(79.3)$ & $89(98.9)$ & \\
\hline Smoking status $[\mathrm{n}(\%)]$ & & & & 0.033 \\
\hline no & $321(36.0)$ & $297(37.0)$ & $24(26.7)$ & \\
\hline yes & $459(51.4)$ & $401(50.0)$ & $58(64.4)$ & \\
\hline quitted & $113(12.7)$ & $105(13.1)$ & $8(8.9)$ & \\
\hline Amount of smoking (pack/year) $(\mathrm{M} \pm \mathrm{SD})$ & $7.7 \pm 10.2$ & $7.5 \pm 10.4$ & $9.3 \pm 8.7$ & 0.008 \\
\hline Presence of complaints $[\mathrm{n}(\%)]$ & $133(14.9)$ & $98(12.2)$ & $35(38.9)$ & $<0.001$ \\
\hline Cough $[\mathrm{n}(\%)]$ & $65(7.3)$ & $48(6.0)$ & $17(18.9)$ & $<0.001$ \\
\hline Sputum $[\mathrm{n}(\%)]$ & $61(6.8)$ & $48(6.0)$ & $13(14.4)$ & 0.003 \\
\hline Shortness of breath $[\mathrm{n}(\%)]$ & $76(8.5)$ & $51(6.4)$ & $25(27.8)$ & $<0.001$ \\
\hline Chest pain $[\mathrm{n}(\%)]$ & $38(4.3)$ & $25(3.1)$ & $13(14.4)$ & $<0.001$ \\
\hline Palpitation $[\mathrm{n}(\%)]$ & $28(3.1)$ & $27(3.4)$ & $1(1.1)$ & 0.349 \\
\hline \multicolumn{5}{|l|}{ Working field and duration } \\
\hline modeling department $[\mathrm{n}(\%)]$ & $775(86.8)$ & $714(88.9)$ & $61(67.8)$ & $<0.001$ \\
\hline work experience (years) $(\mathrm{M} \pm \mathrm{SD})$ & $10.8 \pm 7.5$ & $10.8 \pm 7.4$ & $11.2 \pm 8.5$ & 0.831 \\
\hline leveling and polishing department $[\mathrm{n}(\%)]$ & $566(63.4)$ & $503(62.6)$ & $63(70.0)$ & 0.169 \\
\hline work experience (years) $(\mathrm{M} \pm \mathrm{SD})$ & $8.4 \pm 5.7$ & $8.0 \pm 5.6$ & $11.4 \pm 6.1$ & $<0.001$ \\
\hline plaster and revetment department [n (\%)] & $176(19.7)$ & $174(21.7)$ & $2(2.2)$ & $<0.001$ \\
\hline work experience (years) $(\mathrm{M} \pm \mathrm{SD})$ & $4.1 \pm 3.3$ & $4.1 \pm 3.3$ & $4.0 \pm 1.4$ & 0.636 \\
\hline administrative department $[\mathrm{n}(\%)]$ & $69(7.7)$ & $60(7.5)$ & $9(10.0)$ & 0.394 \\
\hline work experience (years) $(\mathrm{M} \pm \mathrm{SD})$ & $7.7 \pm 6.9$ & $8.2 \pm 7.2$ & $4.1 \pm 2.1$ & 0.139 \\
\hline $\begin{array}{l}\text { Age at the beginning of employment (years) } \\
(\mathrm{M} \pm \mathrm{SD})\end{array}$ & $18.7 \pm 5.3$ & $18.7 \pm 5.3$ & $18.7 \pm 5.9$ & 0.742 \\
\hline Total work experience (years) & $16.1 \pm 8$ & $16.1 \pm 8.1$ & $16.1 \pm 6.8$ & 0.631 \\
\hline$\geq 15$ & $490(54.9)$ & $439(54.7)$ & $51(56.7)$ & 0.718 \\
\hline$\geq 20$ & $286(32.0)$ & $263(32.8)$ & $23(25.6)$ & 0.166 \\
\hline$\geq 30$ & $65(7.3)$ & $62(7.7)$ & $3(3.3)$ & 0.129 \\
\hline Sandblasting [n (\%)] & $171(19.1)$ & $92(11.5)$ & $79(87.8)$ & $<0.001$ \\
\hline
\end{tabular}

DTP - dental technicians' pneumoconiosis.

$\mathrm{M}$ - mean; SD - standard deviation.

* Dental technicians - with DTP vs. without DTP. 
Table 2. Results of pulmonary function tests in those with and without dental technicians' pneumoconiosis

\begin{tabular}{|c|c|c|c|}
\hline Pulmonary function test & $\begin{array}{c}\text { Without DTP } \\
(\mathrm{N}=796)\end{array}$ & $\begin{array}{l}\text { With DTP } \\
(\mathrm{N}=87)\end{array}$ & $\mathrm{p}$ \\
\hline Normal [n (\%)] & $728(91.5)$ & $54(62.1)$ & $<0.001$ \\
\hline Obstructive [n (\%)] & $46(5.8)$ & $25(28.7)$ & \\
\hline Restrictive $[\mathrm{n}(\%)]$ & $22(2.8)$ & $8(9.2)$ & \\
\hline $\mathrm{FEV}(\mathrm{ml})(\mathrm{M} \pm \mathrm{SD})$ & $3.5 \pm 0.7$ & $3.2 \pm 0.8$ & $<0.001$ \\
\hline $\operatorname{FEV}(\%)(\mathrm{M} \pm \mathrm{SD})$ & $95.5 \pm 13.1$ & $83.1 \pm 18.0$ & $<0.001$ \\
\hline $\mathrm{FVC}(\mathrm{ml})(\mathrm{M} \pm \mathrm{SD})$ & $4.2 \pm 0.8$ & $4.1 \pm 0.8$ & 0.158 \\
\hline $\mathrm{FVC}(\%)(\mathrm{M} \pm \mathrm{SD})$ & $96.7 \pm 11.5$ & $89.4 \pm 14.7$ & $<0.001$ \\
\hline Ratio $(\mathrm{M} \pm \mathrm{SD})$ & $83.2 \pm 6.2$ & $78.4 \pm 9.8$ & $<0.001$ \\
\hline $\mathrm{PEF}(\mathrm{ml})(\mathrm{M} \pm \mathrm{SD})$ & $7.5 \pm 1.9$ & $7.2 \pm 2.2$ & 0.294 \\
\hline $\operatorname{PEF}(\%)(\mathrm{M} \pm \mathrm{SD})$ & $85.9 \pm 17.5$ & $78.8 \pm 23.3$ & 0.005 \\
\hline MEF 25-75 (ml) $(\mathrm{M} \pm \mathrm{SD})$ & $4.3 \pm 13.0$ & $3.0 \pm 1.2$ & $<0.001$ \\
\hline MEF $25-75(\%)(\mathrm{M} \pm \mathrm{SD})$ & $86.5 \pm 23.5$ & $65.8 \pm 26.1$ & $<0.001$ \\
\hline MEF $75(\mathrm{ml})(\mathrm{M} \pm \mathrm{SD})$ & $6.9 \pm 1.8$ & $6.0 \pm 2.1$ & $<0.001$ \\
\hline MEF $75(\%)(\mathrm{M} \pm \mathrm{SD})$ & $91.6 \pm 19.8$ & $77.0 \pm 25.9$ & $<0.001$ \\
\hline MEF $50(\mathrm{ml})(\mathrm{M} \pm \mathrm{SD})$ & $5.3 \pm 19.8$ & $3.6 \pm 1.5$ & $<0.001$ \\
\hline MEF $50(\%)(\mathrm{M} \pm \mathrm{SD})$ & $93.1 \pm 28.2$ & $71.4 \pm 29.0$ & $<0.001$ \\
\hline MEF $25(\mathrm{ml})(\mathrm{M} \pm \mathrm{SD})$ & $1.8 \pm 0.8$ & $1.3 \pm 0.7$ & $<0.001$ \\
\hline MEF $25(\%)(\mathrm{M} \pm \mathrm{SD})$ & $79.9 \pm 29.9$ & $59.9 \pm 27.5$ & $<0.001$ \\
\hline
\end{tabular}

FEV - forced expired volume; FVC - forced vital capacity; PEF - peak expiratory flow; MEF - maximal expiratory flow.

Other abbreviations as in Table 1.

Table 3. Evaluation of lung graphs according to the International Labour Organization classification (16) in those with dental technicians' pneumoconiosis

\begin{tabular}{|c|c|c|}
\hline & Variable & $\begin{array}{c}\text { With DTP } \\
(\mathrm{N}=90) \\
{[\mathrm{n}(\%)]}\end{array}$ \\
\hline \multicolumn{3}{|c|}{ Profusion category } \\
\hline 0 & & $0(0.0)$ \\
\hline 1 & & $36(40.0)$ \\
\hline 2 & & $32(35.6)$ \\
\hline 3 & & $22(24.4)$ \\
\hline \multicolumn{3}{|c|}{ Shape and size } \\
\hline $\mathrm{p}$ & & $44(48.9)$ \\
\hline$q$ & & $39(43.3)$ \\
\hline $\mathrm{r}$ & & $4(4.4)$ \\
\hline s & & $1(1.1)$ \\
\hline $\mathrm{u}$ & & $2(2.2)$ \\
\hline
\end{tabular}


Table 3. Evaluation of lung graphs according to the International Labour Organization classification (16) in those with dental technicians' pneumoconiosis - cont.

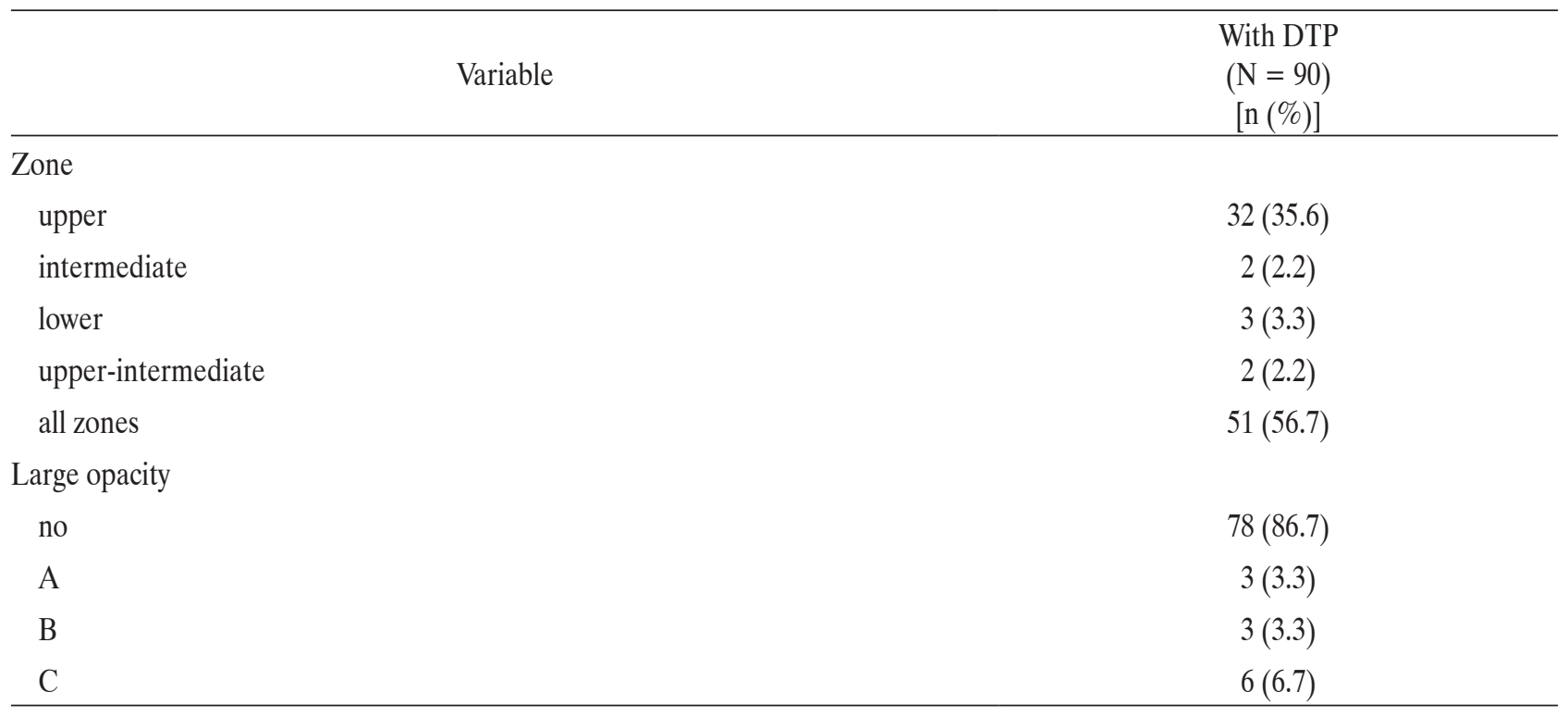

DTP - as in Table 1.

0 - no nodules; 1 - a few nodules without vascular blurring; 2 - a large number of nodules with or without vascular blurring; 3 - a large number of nodules with vascular blurring.

$\mathrm{p}$ - round opacities up to $1.5 \mathrm{~mm}$ in diameter; $\mathrm{q}$ - round opacities $1.5-3 \mathrm{~mm}$ in diameter; $\mathrm{r}$ - round opacities 3-10 mm in diameter; $\mathrm{s}$ - irregular opacities with widths up to about $1.5 \mathrm{~mm} ; \mathrm{t}$ - irregular opacities with widths exceeding $1.5 \mathrm{~mm}$ and up to about $3 \mathrm{~mm}$.

A - one large opacity having the longest dimension up to about $50 \mathrm{~mm}$, or several large opacities with the sum of their longest dimensions not exceeding about $50 \mathrm{~mm}$; B - one large opacity having the longest dimension exceeding $50 \mathrm{~mm}$, but not exceeding the equivalent area of the right upper zone, or several large opacities with the sum of their longest dimensions exceeding $50 \mathrm{~mm}$, but not exceeding the equivalent area of the right upper zone; C - one large opacity which exceeds the equivalent area of the right upper zone, or several large opacities which, when combined, exceed the equivalent area of the right upper zone.

Table 4. High-resolution computed tomography findings in those with and without DTP

\begin{tabular}{lccr}
\hline \multicolumn{1}{c}{ Variable } & $\begin{array}{c}\text { Without DTP } \\
(\mathrm{N}=109) \\
{[\mathrm{n}(\%)]}\end{array}$ & $\begin{array}{c}\text { With DTP } \\
(\mathrm{N}=90) \\
{[\mathrm{n}(\%)]}\end{array}$ & $\mathrm{p}$ \\
\hline Ground glass & $9(8.3)$ & $9(10)$ & 0.670 \\
Hilar LAP & $1(0.9)$ & $18(20)$ & $<0.001$ \\
Mediastinal LAP & $1(0.9)$ & $29(32.2)$ & $<0.001$ \\
Micronodular & $28(25.7)$ & $83(92.2)$ & $<0.001$ \\
Peribronchial thickening & $17(15.6)$ & $8(8.9)$ & 0.155 \\
Air cyst & $5(4.6)$ & $4(4.4)$ & 1.000 \\
Emphysema & $19(17.4)$ & $14(15.6)$ & 0.723 \\
Bronchiectasis & $18(16.5)$ & $11(12.2)$ & 0.393 \\
Atelectasis & $0(0.0)$ & $2(2.2)$ & 0.521 \\
Reticulonodular infiltration & $5(4.6)$ & $34(37.8)$ & $<0.001$ \\
\hline
\end{tabular}


Table 4. High-resolution computed tomography findings in those with and without DTP - cont.

\begin{tabular}{lccr}
\hline \multicolumn{1}{c}{ Variable } & $\begin{array}{c}\text { Without DTP } \\
(\mathrm{N}=109) \\
{[\mathrm{n}(\%)]}\end{array}$ & $\begin{array}{c}\text { With DTP } \\
(\mathrm{N}=90) \\
{[\mathrm{n}(\%)]}\end{array}$ & $\mathrm{p}$ \\
\hline Calcified nodule & $12(11)$ & $13(14.4)$ & 0.467 \\
Linear density increment & $5(4.6)$ & $18(20)$ & 0.001 \\
Interlobular septal thickening & $6(5.5)$ & $24(26.7)$ & $<0.001$ \\
\hline
\end{tabular}

DTP - as in Table 1; LAP - lymphadenopathy.

Table 5. Risk factors for dental technicians' pneumoconiosis

\begin{tabular}{lcc}
\hline \multicolumn{1}{c}{ Variable } & $\mathrm{p}$ & \multicolumn{1}{c}{ OR (95\% CI) } \\
\hline Male gender & 0.040 & $9.207(1.112-76.204)$ \\
Plaster and revetment department & $<0.001$ & $0.337(0.192-0.591)$ \\
Sandblasting & $<0.001$ & $77.309(37.873-157.809)$ \\
\hline
\end{tabular}

OR - odds ratio; CI - confidence interval.

for DTP revealed that male gender and exposure to sandblasting were significant risk factors; however, work experience at plaster and revetment departments was a significant preventive factor. Sandblasting was found to be the greatest risk factor, which increased the rate of DTP development by 77 -fold (Table 5).

\section{DISCUSSION}

It is known that pneumoconiosis results from chronic inhalation of substances which one is exposed to. Nevertheless, the fact is that pneumoconiosis does not develop in everybody exposed to the same substances at the same degree, but it develops in some people, which suggests that there is a genetic predisposition [17]. Illumination of the mechanisms and pathogenesis related to the interaction between genetic and environmental factors is of great importance since it can enable determination of high risk groups and prevention of the disease.

The prevalence of pneumoconiosis among dental technicians has been reported to vary between $4.5 \%$ and 24\% [18-26]. Different study populations (including such as all technicians in the region, only those responding to the questionnaire, only those admitted to hospital), different total and daily working times, and different working environment (it may be considered that large laboratories have better air conditioning and preventive measures) may lead to different prevalence rates for DTP. Choudat et al. [18] evaluated 105 dental technicians. Their X-rays revealed that the prevalence of small opacities $(1 / 0$ or greater), according to ILO classification, was $11.8 \%$ for a mean duration of exposure of 28.4 years. Froudarakis et al. [19] reported the prevalence of pneumoconiosis to be $9.8 \%$ in 51 dental technicians for a mean duration of exposure of 18.6 years. Rom et al. [20] found the prevalence of pneumoconiosis to be $4.5 \%$ in 178 dental technicians for mean work experience of 12.8 years. Selden et al. [21] found the prevalence of DTP at the level of $16 \%$ in their study group $(\mathrm{N}=37)$. Radi et al. [22] reported the prevalence of small opacities with profusion $\geq 1 / 0$ to be $12.3 \%$ in technicians with mean work experience of 16.5 years. Doğan et al. [23] found that prevalence of pneumoconiosis was $13.8 \%$ in dental technicians with a work duration of 13.8 years and it was reported that prevalence increased 
to $47 \%$ after 7 years of a follow-up [26]. Sherson et al. [24] evaluated 31 technicians and found the prevalence of DTP to be $19.4 \%$. Cimrin et al. [25] detected signs of pneumoconiosis in the X-rays of $23.6 \%$ of 140 dental technicians with mean work experience of $12.1 \pm 9$ years. In the present study, the rate of pneumoconiosis was found to be $10.1 \%$ among 893 dental technicians, who were admitted to our hospital in the last 5 years. To the best of our knowledge, the present study had the largest case series reported in dental technicians and evaluated the risk factors through the comparison of the characteristics of the cases with $(\mathrm{N}=90)$ and without $(\mathrm{N}=803)$ DTP. The level of inhalable dust and the concentration of the substances in the dusts show variation among working fields [27]. Therefore, departments in which dental technicians have been working indicate the level of exposure. Radi et al. [22] reported that the most common substances they were exposed to were plaster (93.3\%), wax (83.6\%), nickel-chromium alloys $(82.1 \%)$, silica $(78.9 \%)$ and resin (78.3\%). In their study, Cimrin et al. [25] reported that the frequency of pneumoconiosis was higher in metal flattening, sandblasting and casting sections and indicated that it reached $50 \%$ in workers with a history of sandblasting during their work experience. In the present study, the highest rate of DTP was found in the subjects working in the leveling and polishing department, whereas the lowest rate was found in the subjects working in the plaster and revetment department. The rate of exposure to sandblasting was found to be significantly higher in those with DTP as compared to that in those without DTP ( $87.8 \%$ vs. $11.5 \%, p<0.001)$. In the analysis of the subgroup with a history of sandblasting, pneumoconiosis was found at the rate of $46.1 \%$.

In sandblasting, as the breathable fractions of the particles are separated into even smaller parts with the blast of silica particles after being sprayed with pressured air, their accumulation in the lungs increases as well. The risk of silicosis is high here [28]. As the limit of crystalline silica dust is accepted as $0.05 \mathrm{mg} / \mathrm{m}^{3}$ according to NIOSH, it was demonstrated that this level is exceeded by $200-300$ fold during sandblasting [29-33]. In the present study, it was demonstrated that sandblasting increases the risk of DTP 77-fold, which indicates that dental technicians are heavily exposed to silica. In view of this information, it should be emphasized that the risk of the development of pneumoconiosis is very high in dental technicians.

The relation between the duration of exposure and DTP has been investigated and different results have been reported. Choudat et al. [18] found that the prevalence of DTP was significantly higher $(22.2 \%)$ in those with exposure lasting $\geq 30$ years as compared to those with exposure lasting $<30$ years $(3.5 \%, p<0.004)$. Cimrin et al. [25] reported no significant relationship between the prevalence of DTP and work experience. Also in the present study no significant relationship was found between those with and without DTP in terms of the total work experience. However, the duration of working in the leveling and polishing department was found to be significantly higher in the group with DTP.

The rate of smoking being usually higher among DTP cases makes it difficult to decide how many of the pathological changes result from occupational exposure. Some studies have reported the prevalence of smoking to be higher than 50\% among dental technicians [25]. In the present study, the rate of smoking was found to be 51.4\% and higher in those with DTP as compared to those without DTP. However, smoking was not found as a significant risk factor in the development of DTP. Karaman et al. [34] reported a DTP case, who had never used tobacco or tobacco products in any period of life and whose history revealed no characteristics likely to cause a tendency towards interstitial lung disease, and concluded that existing pathological findings were associated with occupational exposure.

In the present study, $14.9 \%$ of dental technicians had respiratory system-related complaints, out of whom 38.9\% 
had DTP and $12.2 \%$ had no DTP. Respiratory system-related symptoms (cough, sputum, dyspnea and wheezing) were also more frequent among cases with DTP as compared to those without. Cimrin et al. [25] found that $46.7 \%$ of the cases had at least 1 of the respiratory system-related symptoms (26.6\% had cough, 30.4\% had sputum, 18.2\% had dyspnea, and $15.0 \%$ had wheezing). They failed to find a significant correlation between the rate of pneumoconiosis and the presence of the respiratory system symptoms.

In their study conducted on dental technicians and ageand-smoking status-matched controls, Doğan et al. [23] found no difference between the groups in terms of respiratory system symptoms (cough, sputum, dyspnea, wheezing) and PFTs, except for $\mathrm{FEV}_{1}$. Radi et al. [22] conducted a study on 134 dental technicians and 131 nonexposed subjects and reported significant risks for cough (day and night) and usual phlegm in dental technicians. Moreover, they found that $\mathrm{FVC} \%$, forced mid expiratory flow $\left(\mathrm{FEF}_{25 \%}\right)$, and $\mathrm{FEF}_{50 \%}$ values were significantly lower in the dental technicians group as compared to those in the non-exposed group. In the present study, the results of PFTs, except for FVC (ml) and PEF (ml) were significantly lower in those with DTP as compared to those without it. The rate of impaired PFT (obstructive, restrictive) was found to be higher in the subjects with DTP than that in the subjects without DTP.

Since exposure to multiple substances occurs in DTP, it can be assumed that there would be a diversity in the radiological findings. In the present study, $40 \%$ of DTP cases had profusion category 1 and $48.9 \%$ had small p opacity; all zones were involved in 56.7\%. Froudarakis et al. [19] found DTP in 5 cases, out of whom 1 had 2/2 ILO profusion and diffuse irregular opacities (sr) and 4 had regular small opacities (pq) localized on the upper lobes. They noted no pleural changes. Radi et al. [22] detected a large opacity in 3.8\%. Among the subjects with DTP, 12 (13.3\%) had a large opacity; this was also one of the remarkable findings of the present study.
In the silicosis case reported by Boyraz and Akın [35], HRCT revealed high-density millimetric nodules extensive in both lungs, but denser in the upper zones, nodular densities showing conglomeration in the upper zones and consistent with progressive massive fibrosis, mediastinal and hilar multiple lymph nodes enlargements containing remarkable calcifications. In the present study, HRCT examination revealed that the rate of subjects with hilar and mediastinal lymph nodes enlargement, micronodule, reticulonodular infiltration, linear density increment, and interlobular septal thickening was significantly higher in the DTP group.

One potential limitation of this study was that the dose and incidence of the occupational exposure were not quantified. Although we used well defined criteria for diagnosis, the study lacks pathological confirmation. Another limitation is that our patient group may not represent the entire population of dental laboratory technicians. However, we believe that we met our aim to define the clinical and the radiological features of pneumoconiosis in dental laboratory technicians.

\section{CONCLUSIONS}

The rate of DTP was $10.1 \%$, the highest profusion category was $3 /+$, and the rate of large opacities was $13.3 \%$ in the present study. To the best of our knowledge, this is the largest DTP case series $(\mathrm{N}=90)$ in the literature and we noted that the disease was more common among males and especially in those exposed to sandblasting who had a 77-fold higher risk of DTP. Occupational evaluation should be considered as supplementary to the clinical, radiological and pathological evaluation of the patients with suspected pneumoconiosis. Health screenings should be performed regularly for the early diagnosis of pneumoconiosis, which is an important occupational disease for dental technicians. Moreover, dental technicians should be encouraged to use the protecting materials adequately and ought to be regularly trained on this issue. 


\section{REFERENCES}

1. Fasunloro A, Owotade FJ. Occupational hazards among clinical dental staff. J Contemp Dent Pract. 2004;5(2):134-52.

2. Gambhir RS, Singh G, Sharma S, Brar R, Kakar R. Occupational health hazards in current dental profession - A review. Open Occup Health Saf J. 2011;3:57-64, http://dx.doi. org/10.2174/1876216601103010057.

3. Choudat D. Occupational lung diseases among dental technicians. Tuber Lung Dis. 1994;75:99-104, http://dx.doi. org/10.1016/0962-8479(94)90037-X.

4. Thorette C, Grigoriu B, Canut E, Sobaszek A, Tonnel AB, Tillie-Leblond I. [Pulmonary disease in dental laboratory technicians]. Rev Mal Respir. 2006;23 Suppl 2:4S7-4S16, http://dx.doi.org/10.1019/200530228. French.

5. Pipavath SN, Godwin JD, Kanne JP. Occupational lung disease: A radiologic review. Semin Roentgenol. 2010;45(1): 43-52, http://dx.doi.org/10.1053/j.ro.2009.07.008.

6. Centers for Disease Control and Prevention. Silicosis in dental laboratory technicians - Five states, 1994-2000. Morb Mortal Wkly Rep. 2004;53(9):195-7.

7. Dos Santos Antao VC, Pinheiro GA, Parker JE. Lung diseases associated with silicates and other dusts. In: Rom WN, editor. Enviromental and Occupational Medicine. 4th ed. Philadelphia: Lippincott Williams \& Wilkins; 2007. p. 527.

8. Barboza CE, Winter DH, Seiscento M, Santos Ude P, Terra Filho M. [Tuberculosis and silicosis: Epidemiology, diagnosis and chemoprophylaxis]. J Bras Pneumol. 2008 Nov;34(11):959-66, http://dx.doi.org/10.1590/S1806-3713200 8001100012. Portuguese.

9. Kazan-Allen L. Asbestos and mesothelioma: Worldwide trends. Lung Cancer. 2005;49 Suppl 1:S3-8, http://dx.doi. org/10.1016/j.lungcan.2005.03.002.

10. Kurihara N, Wada O. Silicosis and smoking strongly increase lung cancer risk in silica-exposed workers. Ind Health. 2004;42(3):303-14, http://dx.doi.org/10.2486/indhealth.42.303.

11. Pelucchi C, Pira E, Piolatto G, Coggiola M, Carta P, la Vecchia C. Occupational silica exposure and lung cancer risk:
A review of epidemiological studies 1996-2005. Ann Oncol. 2006;17(7):1039-50, http://dx.doi.org/10.1093/annonc/mdj125.

12. Akira M. Imaging of occupational and environmental lung diseases. Clin Chest Med. 2008 March;29(1):117-31, http:// dx.doi.org/10.1016/j.ccm.2007.11.001.

13. Sirajuddin A, Kanne JP. Occupational lung disease. J Thorac Imaging. 2009;24(4):310-20, http://dx.doi.org/10.1097/ RTI.0b013e3181c1a9b3.

14. Muzaffar S, Kales SN. What are the major points and emerging issues in radiologic imaging for pneumoconiosis surveillance and diagnosis? J Occup Environ Med. 2008;50(1): 101-4, http://dx.doi.org/10.1097/JOM.0b013e31813c6868.

15. American Thoracic Society. Standardization of Spirometry, 1994 update. Am J Respir Crit Care Med. 1995;152(3): 1107-36, http://dx.doi.org/10.1164/ajrccm.152.3.7663792.

16. International Labour Office. Guidelines for the use of the ILO International Classification of Radiographs of Pneumoconioses. ILO Occupational Safety and Health Series No. 22. Revised edition. Geneva: ILO; 2011. p. 1-11.

17. Yucesoy B, Luster MI. Genetic susceptibility in pneumoconiosis. Toxicol Lett. 2007;168(3):249-54, http://dx.doi. org/10.1016/j.toxlet.2006.10.021.

18. Choudat D, Triem S, Weill B, Vicrey C, Ameille J, Brochard P, et al. Respiratory symptoms, lung function, and pneumoconiosis among self employed dental technicians. Br J Ind Med. 1993;50:443-9.

19. Froudarakis ME, Voloudaki A, Bouros D, Drakonakis G, Hatzakis K, Siafakas NM. Pneumoconiosis among Cretan dental technicians. Respiration. 1999;66:338-42, http:// dx.doi.org/10.1159/000029404.

20. Rom WN, Lockey JE, Lee JS, Kimball AC, Bang KM, Leaman H, et al. Pneumoconiosis and exposure of dental laboratory technicians. Am J Public Health. 1984;74:1252-7, http://dx.doi.org/10.2105/AJPH.74.11.1252.

21. Selden AI, Persson B, Bornberger-Dankvardt S, Winström LE, Bodin LS. Exposure to cobalt chromium dust and lung disorders in dental technicians. Thorax. 1995;50: 769-72, http://dx.doi.org/10.1136/thx.50.7.769. 
22. Radi S, Dalphin JC, Manzoni P, Pernet D, Leboube MP, Viel JF. Respiratory morbidity in a population of French dental technicians. Occup Environ Med. 2002;59:398-404, http://dx.doi.org/10.1136/oem.59.6.398.

23. Doğan DÖ, Ozdemir AK, Polat NT, Dal U, Gümüş C, Akkurt I. Prevalence of respiratory abnormalities and pneumoconiosis in dental laboratory technicians. Tuberk Toraks. 2010;58:135-41.

24. Sherson D, Maltbaek N, Olsen O. Small opacities among dental laboratory technicians in Copenhagen. $\mathrm{Br} \mathrm{J}$ Ind Med. 1988;45:320-4.

25. Cimrin A, Komus N, Karaman C, Tertemiz KC. Pneumoconiosis and work-related health complaints in Turkish dental laboratory workers. Tuberk Toraks. 2009;57:282-8.

26. Dogan DÖ, Berk S, Gumus C, Ozdemır AK, Akkurt I. A longitudinal study on lung disease in dental technicians: What has changed after seven years?. Int J Occup Med Environ Health. 2013;26(5):693-701, http://dx.doi.org/10.2478/ s13382-013-0140-0.

27. Kim TS, Kim HA, Heo Y, Park Y, Park CY, Roh YM. Level of silica in the respirable dust inhaled by dental technicians with demonstration of respirable symptoms. Ind Health. 2002;40:260-5.

28. Koga T, Hirano K, Masuzaki M, Komiya Y, Tsuiki S. Three patients with typical sandblaster's silicosis proven by mineralogical analysis. Nippon Kyobu Shikkan Gakkai Zasshi. 1990;28(8):1098-105.
29. National Institute for Occupational Safety and Health Alert: Request for assistance in preventing silicosis and deaths from sandblasting. Cincinnati, Ohio: US Department of Health and Human Services, Public Health Service, Centers for Disease Control and Prevention; 1992. p. 92-102.

30. Rosenman KD, Reilly MJ, Kalinowsky DJ, Watt FC. Silicosis in the 1990s. Chest. 1997;111(3):779-86, http://dx.doi. org/10.1378/chest.111.3.779.

31. Abraham JL, Wiesenfeld SL. Two cases of fatal PMF in an ongoing epidemic of accelerated silicosis in oilfield sandblasters: Lung pathology and mineralogy. Ann Occup Hyg. 1997;41:440-7, http://dx.doi.org/10.1093/annhyg/41.inhaled_particles_VIII.440.

32. Glindmeyer HW, Hammad YY. Contributing factors to sandblasters' silicosis: Inadequate respiratory protection equipment and standards. J Occup Med. 1988;30:917-21, http://dx.doi.org/10.1097/00043764-198812000-00007.

33. Sevinc C, Cimrin AH, Manisali M, Yalcin E, Alkan Y. Sandblasting under uncontrolled and primitive conditions in Turkey. J Occup Health. 2003;45(1):66-9, http://dx.doi. org/10.1539/joh.45.66.

34. Karaman EC, Itil O, Gülşen A, Kargı A, Cimrin A. Dental technician's pneumoconiosis: A case report. Tuberk Toraks. 2008;56:204-9.

35. Boyraz E, Akın M. High-resolution computed tomography findings of a silicosis patient working at a dental prosthesis laboratory. Cumhuriyet Med J. 2010;32:352-6.

This work is available in Open Access model and licensed under a Creative Commons Attribution-NonCommercial 3.0 Poland License - http:/creativecommons.org/ licenses/by-nc/3.0/pl/deed.en. 